\title{
Volar ulnar approach to the distal radius and carpus
}

\author{
Nicholas Pourgiezis ${ }^{1,2}$, Gregory I Bain MBBS FRACS ${ }^{1}$, James H Roth MD FRCSC FRCS ${ }^{3}$, \\ Michael R Woolfrey MD ${ }^{3}$ \\ ${ }^{1}$ Modbury Public Hospital, Smart Road, Modbury, South Australia; ${ }^{2}$ University of Adelaide, North \\ Terrace, Adelaide, South Australia, Australia; ${ }^{3}$ Hand and Upper Limb Centre, St Joseph's Health \\ Centre, Division of Orthopaedic Surgery, Department of Surgery and The University of Western \\ Ontario, London, Ontario
}

\section{N Pourgiezis, GI Bain, JH Roth, MR Woolfrey. Volar ulnar approach to the distal radius and carpus. Can J Plast Surg 1999;7(6):273-278.}

This safe and extensile approach provides excellent exposure of the flexor tendons in the palm, distal radius, distal radioulnar joint and carpus, and can be used to expose any pathology on the volar aspect of the wrist. Using a volar ulnar incision, the ulnar neurovascular bundle is identified and extensively released. The transverse carpal ligament is divided at its ulnar attachment, and the finger flexor tendons are retracted radially to expose the volar wrist capsule and the pronator quadratus. These latter structures can be divided to expose the carpus and distal radius, respectively. Forty-four patients were reviewed, and 46 procedures were performed. The approach was used for a spectrum of indications and often included complex injuries or disorders of the wrist. Patients reported a low level of pain and a high level of satisfaction. There were no neurovascular complications.

Key Words: Approach; Carpus; Radius

\section{Voie d'abord cubitale antérieure au radius distal et au carpe}

RÉSUMÉ : Cette voie d'abord sûre et extensible procure une exposition excellente des tendons fléchisseurs de la paume, du radius distal, de l'articulation radio-cubitale distale et du carpe, et peut être utilisée pour exposer n'importe quelle pathologie touchant la face antérieure du poignet. En procédant à une incision cubitale antérieure, le paquet vasculo-nerveux est identifié et libéré de façon considérable. Le ligament carpien transverse est divisé à son attache cubitale, et les tendons fléchisseurs du doigt sont rétractés du côté radial pour exposer la capsule antérieure du poignet et le muscle carré pronateur. Ces dernières structures peuvent être divisées pour exposer, respectivement, le carpe et le radius distal. Quarante-quatre patients ont été passés en revue et 46 interventions ont été pratiquées. Cette voie d'abord a été utilisée pour un éventail d'indications et souvent lors de blessures complexes ou d'atteintes du poignet. Les patients ont rapporté un niveau de douleur bas et un niveau de satisfaction élevé. Il n'y avait aucune complications neuro-vasculaires.

$\mathrm{E}^{\mathrm{x}}$ xposure of the volar aspect of the distal radius is commonly required for the management of distal radius fractures. Most authors have approached the distal radius on the radial side of the flexor tendons $(1,2,3,4)$. Recently some authors have reported approaching the distal radius on the ulnar side of the flexor tendons $(5,6)$. Many approaches to different aspects of the distal radius and carpus have been reported; however, none of these can be used as a universal approach to all pathologies in this region $(1,4,5,7)$.

Correspondence: Dr GI Bain, 206 Melbourne Street, North Adelaide, South Australia, Australia 5006. Telephone +61-88-361-8399, fax+61-88-239-2237,e-mail orthodoc@ctel.com.au
This technique is a universal approach to the volar aspect of the distal radius and carpus. It decompresses the ulnar and median nerves, and provides excellent exposure to the volar aspect of the distal radius and carpus while avoiding important neurological structures in this region.

This study reviews the results of the volar ulnar approach to the distal radius and carpus applied to a consecutive group of patients.

\section{MATERIALS AND METHODS}

\section{Patients}

A standardized technique to the distal radius and carpus was prospectively performed on 51 patients by one surgeon between December 1994 and June 1997. Two patients had the 


\section{TABLE 1}

Indications for volar ulnar approach to the distal radius and carpus

\begin{tabular}{|c|c|}
\hline Procedure & Number of procedures \\
\hline \multicolumn{2}{|l|}{ Guyon's canal } \\
\hline Decompression & 1 \\
\hline $\begin{array}{l}\text { Excision of space-occupying } \\
\text { lesion }\end{array}$ & 1 \\
\hline \multicolumn{2}{|l|}{ Carpal tunnel } \\
\hline Decompression & 16 \\
\hline $\begin{array}{l}\text { Excision of space-occupying } \\
\text { lesion }\end{array}$ & 5 \\
\hline Neurolysis & 5 \\
\hline \multicolumn{2}{|l|}{ Flexor tendon } \\
\hline Repair or reconstruction & 1 \\
\hline Tenolysis & 3 \\
\hline Infective tenosynovitis & 2 \\
\hline \multicolumn{2}{|l|}{ Carpus } \\
\hline $\begin{array}{l}\text { Perilunate dislocation (decompression } \\
\text { of carpal tunnel and repair of volar } \\
\text { ligament) }\end{array}$ & 5 \\
\hline Intraosseous ganglion excision & 2 \\
\hline Excision of hook of hamate nonunion & 1 \\
\hline \multicolumn{2}{|l|}{ Distal radius } \\
\hline $\begin{array}{l}\text { Open reduction internal fixation of } \\
\text { Barton's fracture }\end{array}$ & 6 \\
\hline Removal of buttress plate & 1 \\
\hline \multicolumn{2}{|l|}{ Distal radio-ulnar joint } \\
\hline Volar dislocation of distal ulnar & 1 \\
\hline \multicolumn{2}{|l|}{ Forearm } \\
\hline Fasciotomy & 1 \\
\hline Distal ulnar fracture & 1 \\
\hline \multicolumn{2}{|l|}{ Other } \\
\hline Removal of foreign body & 1 \\
\hline Total number of procedures performed & 53 \\
\hline
\end{tabular}

procedure performed on both wrists. Forty-four patients were available for follow-up (86\% patient follow-up, 90\% procedure follow-up). Indications for operative treatment using the volar ulnar approach to the distal radius and carpus are listed in Table 1.

Twenty-eight of the patients available at follow-up (64\%) were male, and $18(36 \%)$ were female, the average age was 50 years, range 17 to 90 years. Twenty-two procedures $(48 \%)$ were performed on the left wrist, and $24(52 \%)$ on the right. Twenty-five procedures $(54 \%)$ were performed on the dominant extremity. Average duration of follow-up was 14 months, range three months to 33 months).

\section{Operative technique}

This surgical technique was developed as a safe and extensile approach to the volar aspect of the wrist. The approach is made with the aid of loupe magnification and a tourniquet on

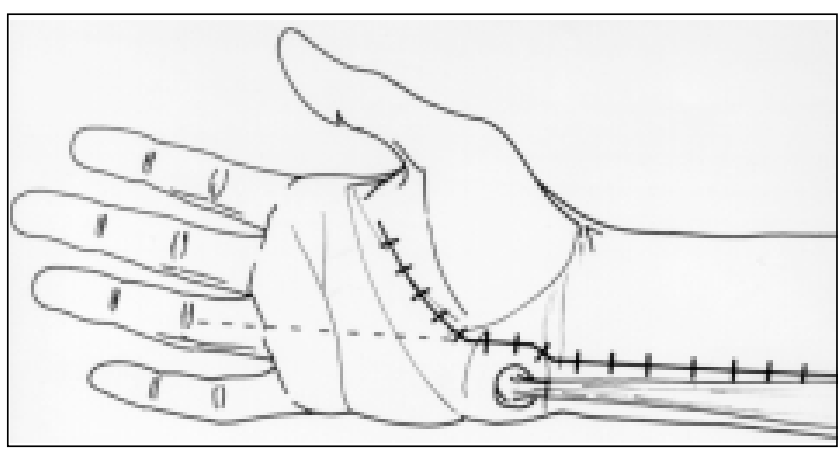

Figure 1) Skin incision for volar ulnar approach to the distal radius and carpus. In the forearm the incision is just radial to the flexor carpi ulnaris tendon and crosses the wrist skin creases obliquely. It passes across the transverse carpal ligament along the line of the ring finger and enters the palm just ulnar to the thenar crease

the upper arm. The incision is made immediately radial to the flexor carpi ulnaris tendon and the pisiform, and crosses the flexion crease of the wrist at $45^{\circ}$. It crosses the transverse carpal ligament in the line of the ring finger and then curves to the radial side, just distal to the thenar crease (Figure 1).

Blunt dissection is used to divide the subcutaneous tissue so that any cutaneous nerves can be identified. The antebrachial fascia is divided on the radial side of the flexor carpi ulnaris tendon, and the ulnar neurovascular bundle is identified just radial and deep to this tendon. The ulnar neurovascular bundle is released from the forearm to the palm by dividing the antebrachial fascia, the volar carpal ligament, which forms the roof of Guyon's canal, and the palmar aponeurosis which overlies the superficial palmar arch. Multiple small vessels on the radial side of the ulnar neurovascular bundle are divided with bipolar cautery to allow it to be retracted in an ulnar direction to expose the ulnar attachment of the transverse carpal ligament (Figure 2). The hook of the hamate is easily palpated and is a good landmark to the ulnar border of the flexor retinaculum, which is then divided. Surgical excision of a hook of hamate nonunion is simple to perform because the hook of hamate is exposed from the radial and ulnar aspects.

The surgeon's finger is used to separate the finger flexor tendons from the ulnar neurovascular bundle and flexor carpi ulnaris. Flexion of the wrist allows the flexor tendons and median nerve to be delivered from the carpal tunnel. The synovial membranes surrounding the flexor tendons are not disturbed unless the individual flexor tendons require exposure. One or two Hohmann retractors are placed to the radial side of the radius to retract the flexor tendons and expose the pronator quadratus (Figures 3,4). The pronator quadratus is divided with cautery over the radius and then reflected subperiosteally to provide exposure of the distal radius (Figure 5). An alternative is to release the pronator quadratus from its most radial insertion. The carpus can be exposed by dividing the volar carpal ligaments.

The exposure can be extended proximally between the finger flexor tendons and the flexor carpi ulnaris to perform a 


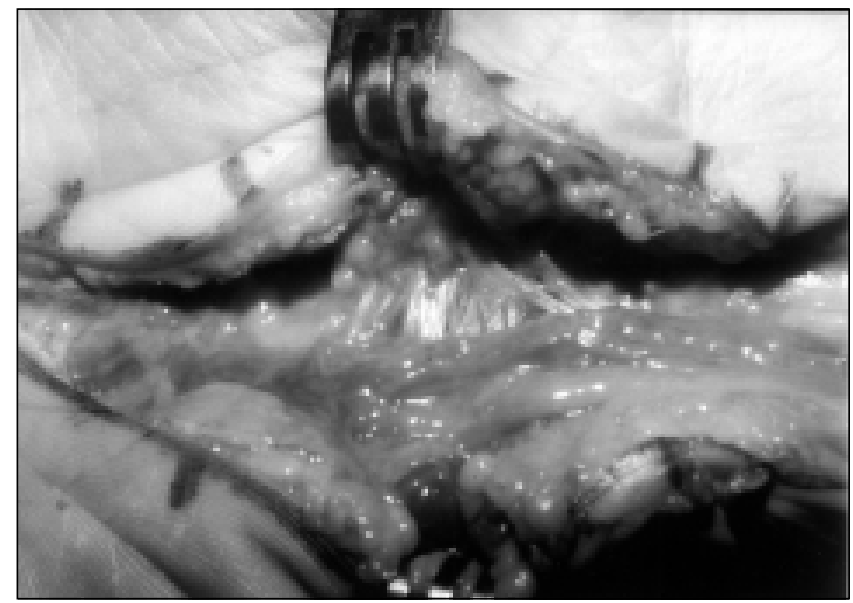

Figure 2) The ulnar neurovascular bundle is identified proximally beneath the flexor carpi ulnaris tendon and followed distally into Guyon's canal. Multiple small vessels on the radial side of the ulnar neurovascular bundle are divided to allow it to be retracted to expose the ulnar attachment of the transverse carpal ligament

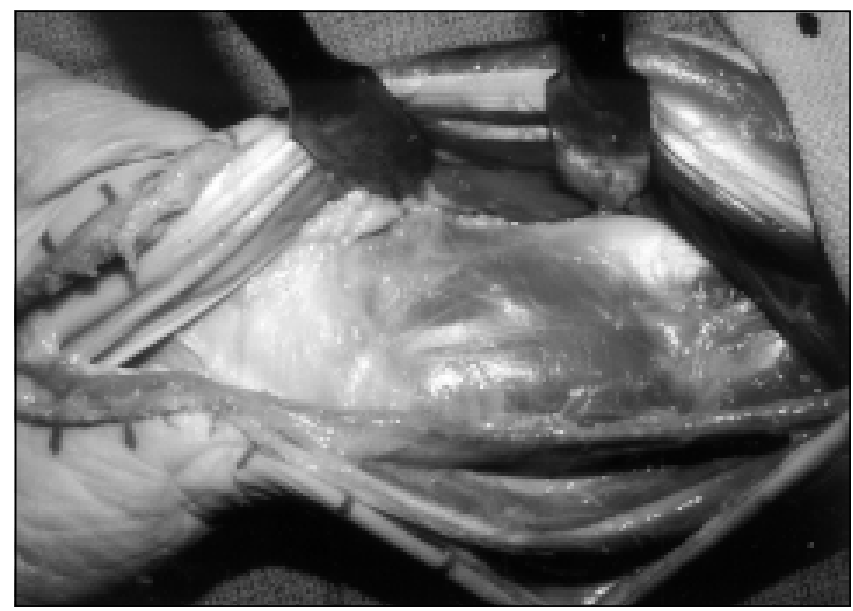

Figure 3) With the transverse carpal ligament divided, flexion of the wrist and retraction of the flexor tendons with Hohmann retractors (Hohmann Medical Equipment, Bensheim, Germany) exposes the pronator quadratus and wrist capsule

fasciotomy or to expose the shaft of the ulna. Distally, the exposure is limited by the superficial palmar arch at the distal aspect of the outstretched thumb (8).

\section{Analysis of patients}

Patient assessments were performed by an independent investigator using a standardized protocol. Each patient was asked to categorize and indicate on a visual analogue scale (VAS) the level of pain experienced. The VAS was a $10 \mathrm{~cm}$ long line marked with no pain at one end and severe pain at the other. Subjective evaluation included questioning regarding specific activities of daily living. Each patient was asked to categorize their ability to perform these tasks. A total of 10 activities were scored, and this was recorded as a sum of activities of daily living difficulty, range 0 to 30 . Patients' ability to perform their usual work activities and engage in usual sport or recreation was categorized as able, able to perform at lower than previous level, or unable to perform. Completing

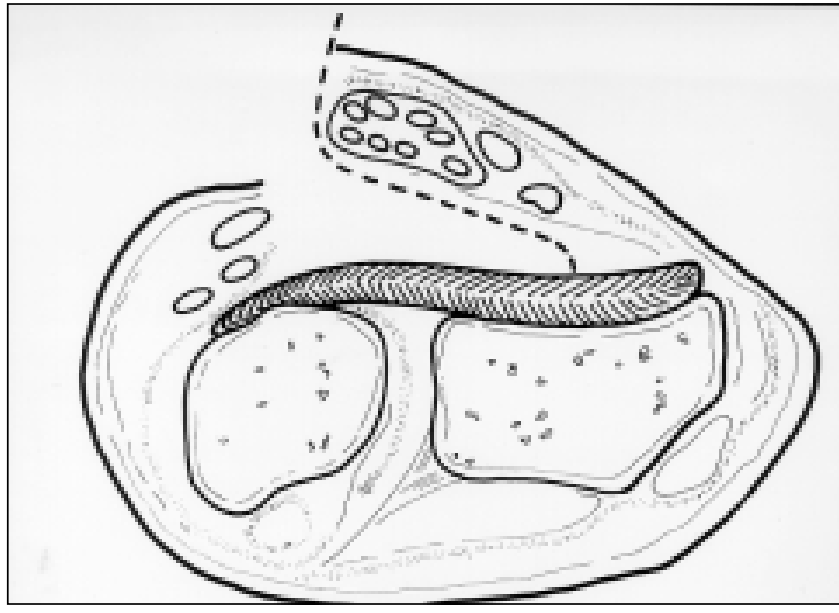

Figure 4) Cross section diagram of the distal forearm showing the interval for the volar ulnar approach to the distal radius and carpus

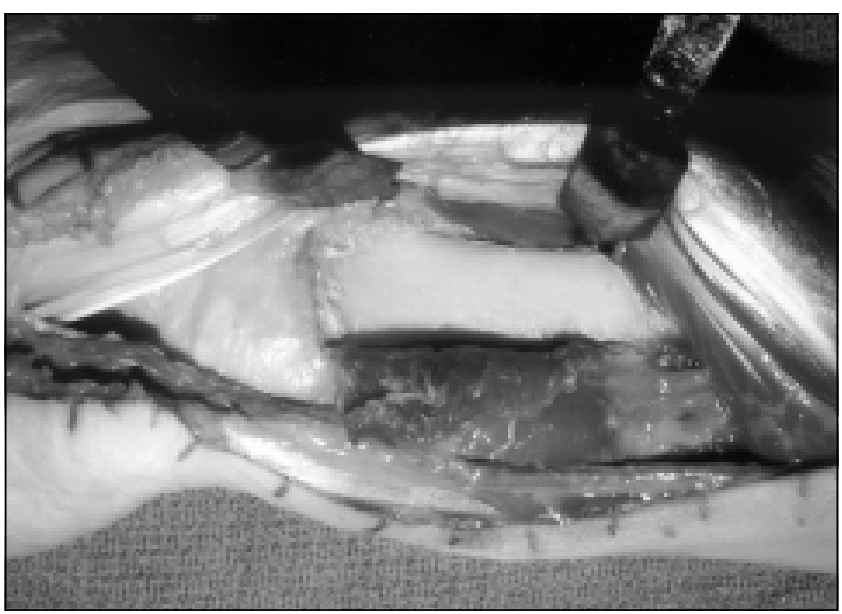

Figure 5) The pronator quadratus muscle has been reflected from the radius. It is usually divided with cutting cautery over the radius and reflected subperiosteally

the subjective evaluation, each patient was asked to rate their level of satisfaction with the outcome of surgery on a VAS numbered from 0 to 10 , with zero indicating extreme dissatisfaction and 10 indicating extreme satisfaction.

Active range of motion was assessed using a handheld goniometer including flexion, extension, radial deviation, ulnar deviation, supination and pronation of the wrist. Grip strength was assessed using a Jamar Dynamometer on the second position (Preston, Jackson, Mississippi), with the elbow flexed to $90^{\circ}$ and held at the side of the body with the forearm in neutral rotation. Pinch strength was assessed with a calibrated pinch meter (Preston) and included tip pinch, lateral pinch and chuck (three-finger) pinch. A similar limb position was assumed as for grip strength testing, varying only in forearm rotation; full pronation of the forearm was assumed for tip and chuck pinch (9). An examination for complications was also undertaken.

Patients who had surgery (Cases $10,11,13,14)$ or signifi- 
Table 2

Comparison of measurements between affected and contralateral extremity, for patients being treated by the volar ulnar approach to the distal radius and carpus

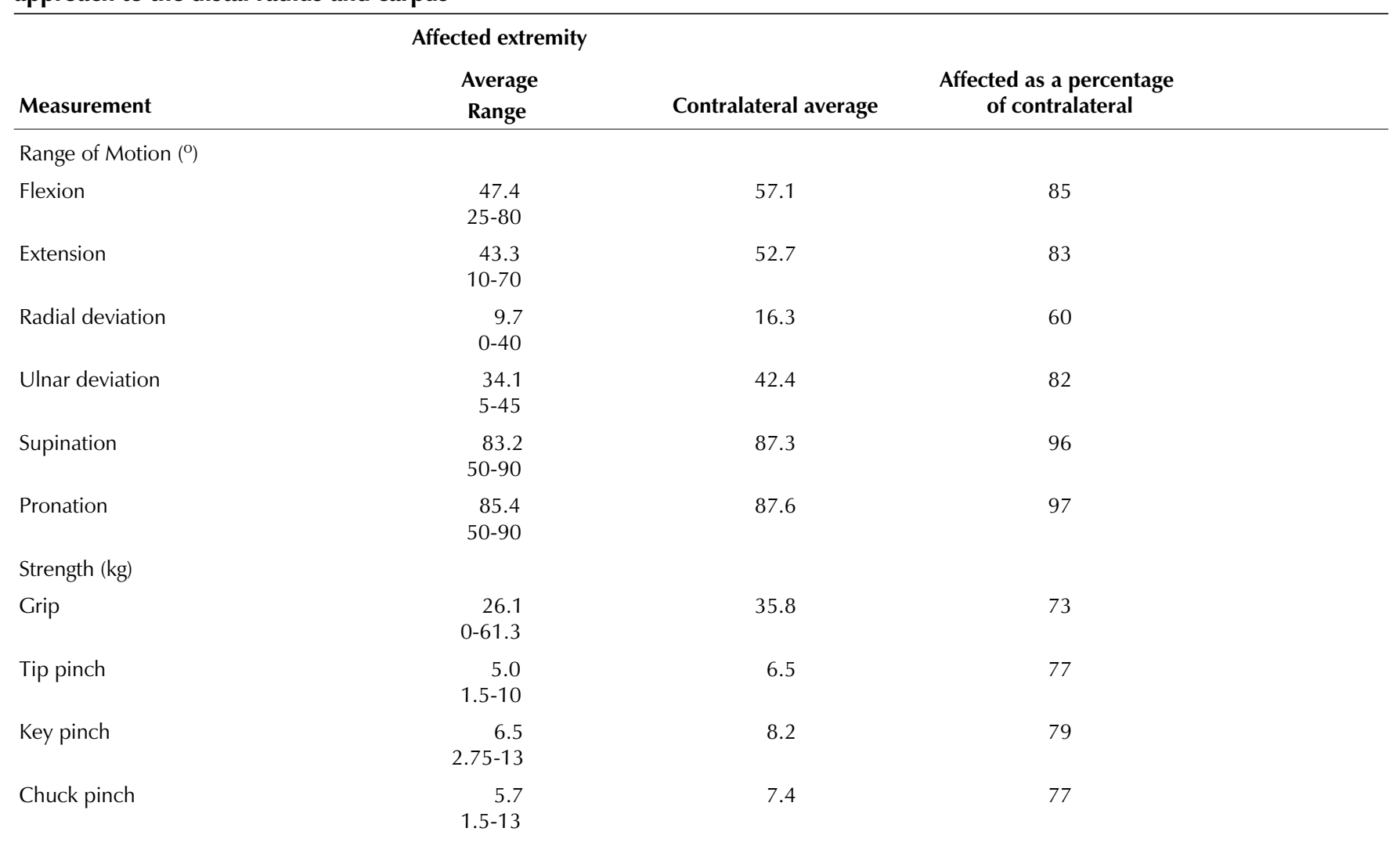

cant injuries (Case 21) to the contralateral extremity were excluded from assessment when comparing results with the contralateral extremity such as range of motion, and grip and pinch strengths. One case (Case 31) had undergone a limited wrist fusion following the volar ulnar approach operation and, therefore, range of motion measurements were excluded from analysis.

\section{RESULTS}

Twenty-two patients stated that they had no pain in the operated wrist, 11 had slight pain, seven reported moderate pain and four reported severe pain. Using a VAS (0 to 10), the average pain score was 2.2. Thirty-four patients reported that they were satisfied with the outcome of surgery. The average VAS score for satisfaction was 8.0. The average sum of difficulty in performing activities of daily living was 3.9 of a possible 30 .

Thirty-one patients had returned to their previous occupation without restrictions; five patients had returned to their previous occupation but were restricted in their duties because of sequelae related to their initial injuries. These included patients with perilunate dislocation (Case 19), excision of intraosseous ganglion (Case 29), comminuted fracture dislocation of the distal radius (Case 30 ) and crush injury to the hand (Cases 31 and 36).

Four patients had returned to their previous occupation but were restricted in their duties at work as a result of the surgery. All four patients were on Workers' Compensa- tion. Two patients (Cases 10,11,13,14) were also restricted in their normal work duties following procedures on both wrists. Two patients (Cases 17 and 21) were unable to return to their usual occupation in any capacity as a result of multiple injuries. Twenty-six patients were able to perform leisure activities without any restrictions, 10 were able to perform their leisure activities in a reduced capacity and eight were unable to perform their usual leisure activities.

The active range of motion and percentage of the contralateral wrist were flexion $47^{\circ}(85 \%)$, extension $43^{\circ}(83 \%)$, radial deviation $10^{\circ}(60 \%)$, ulnar deviation $34^{\circ}(82 \%)$, supination $83^{\circ}$ $(96 \%)$ and pronation $85^{\circ}(97 \%)$. This represents an average of $84 \%$ of the range of motion of the contralateral extremity. The average strength and percentage of contralateral wrist were grip $26 \mathrm{~kg}(73 \%)$, tip pinch $5 \mathrm{~kg}(77 \%)$, key pinch $6.5 \mathrm{~kg}$ (79\%) and chuck pinch $5.7 \mathrm{~kg}(77 \%)$. This represents an average of $77 \%$ of the strength of the contralateral extremity.

All 44 patients had operative scars that were unremarkable in appearance. A summary table of results including range of motion and strength measurements is presented in Table 2. One infection (Case 2) occurred in the early postoperative period but did not affect the long term result. There were no neurovascular complications. There were a number of cases where the results were compromised as a consequence of the initial injury; however, there was no case in which the results appeared compromised as a consequence of the surgical approach. 


\section{DISCUSSION}

In this study, the volar ulnar approach was used for a spectrum of indications and often included complex injuries or disorders of the wrist. Patients reported a low level of pain, a high level of satisfaction, and the majority were able to return to their work and activities of daily living. These results indicate that this approach enables a return of the functional range of motion and strength.

Although ulnar neuropathy can be associated with distal radial fractures and carpal tunnel syndrome, Guyon's canal is usually not released as a prophylactic measure (10-14). In this approach, Guyon's canal is released as a means of ensuring that the ulnar attachment of the transverse carpal ligament is well visualised without risk to the ulnar neurovascular bundle. The ulnar neurovascular bundle is close to the line of the ring finger and can be injured if it is not identified during exposure of the flexor retinaculum. We recommend that the volar ulnar approach be used for carpal tunnel release if the patient has paraesthesia involving the ulnar side of the hand. This ensures that the ulnar nerve is also released.

The flexor retinaculum is routinely released when approaching the distal radius and carpus because it allows the flexor tendons to be retracted, which greatly enhances the exposure. It also decompresses the median nerve, which can be compromised following fractures of the distal radius and dislocations of the carpus $(1,11,15)$. The flexor retinaculum is released at its ulnar attachment to prevent injury to the recurrent motor branch of the median nerve and the palmar cutaneous branch of the median nerve and to avoid bowstringing of the flexor tendons (16-19). Poisel (20), reported that the recurrent motor branch courses through the transverse carpal ligament in $23 \%$ of cases. Lanz (21) advised that the median nerve be approached from the ulnar side to prevent injury to the recurrent motor branch. Taleisnik (7) reported that branches of the palmar cutaneous branch of the median nerve are visible within and on the surface of the flexor retinaculum immediately radial to the axis of the ring finger. MacDonald et al (8) advised that dividing the transverse carpal ligament at its ulnar attachment minimized the risk of bowstringing of the flexor tendons.

The palmar cutaneous branch of the median nerve is at risk during surgical procedures at the level of the wrist $(17,20,22)$. Hobbs et al reported that the palmar branch of the median nerve passes between flexor carpi radialis and palmaris longus to penetrate or lie superficial to the flexor retinaculum and supply the palmar skin ulnar to the axial line of the ring finger (7). Many authors have recommended that the carpal tunnel be decompressed though an incision placed along the line of the ring finger to avoid injury to the palmar cutaneous branch of the median nerve and the palmar cutaneous branch of the ulnar nerve $(17,21,22)$. We have adopted this recommendation for the component of the incision, that crosses the wrist.

Other authors have reported approaches to different aspects of the distal radius or carpus, but none of these can be used as a universal approach to all pathologies in this region $(1,4,5,7)$. Hastings and Leibovic (5) describe approaching the volar as- pect of distal radial fractures between the ulnar neurovascular bundle and the flexor digitorum profundus tendons. However, no comment is made regarding the release of the ulnar or median nerves or exposure of the carpus. Hoppenfeld and De Boer (4) describes an approach to Guyon's canal and another to the volar aspect of the forearm. Rowland (23) describes a forearm fasciotomy that includes releasing the flexor retinaculum. Unlike these other methods, the volar ulnar approach is a universal approach, which provides exposure to the median and ulnar nerves, flexor tendons, distal radius, distal radioulnar joint and carpus. In addition, it is an extensile approach proximally and distally to the superficial palmar arch.

In conclusion, the volar ulnar approach to the distal radius is a universal approach to the volar aspect of the distal radius and carpus, that can be used to expose any pathology in this region. This approach decompresses the ulnar and median nerves at the level of the wrist, and provides excellent exposure of the flexor tendons, distal radius, distal radioulnar joint and carpus. It is extensile both proximally and distally. It is a safe approach that avoids injury to the palmar cutaneous branches of the median nerve and ulnar nerves, and the recurrent motor branch of the median nerve.

ACKNOWLEDGEMENT: The authors thank Mr Ron Heptinstall for assistance with preparation of the manuscript and Ms Christine Zanuto for the art work.

\section{REFERENCES}

1. Axelrod TS, McMurtry RY. Open reduction and internal fixation of comminuted intra-articular fractures of the distal radius. J Hand Surg [Am] 1990;15A:1-11.

2. Crenshaw AH. Campbell's Operative Orthopedics. St Louis: Mosby, 1987:102-5.

3. Henry AK. Extensile Exposure. Edinburgh and London: Churchill Livingstone, 1973:100-11.

4. Hoppenfeld S, De Boer P. Surgical Exposures in Orthopedics: The Anatomical Approach. Philadelphia: JB Lippincott Company, 1984:153-70.

5. Hastings H, Leibovic SJ. Indications and techniques of open reduction: Internal Fixation of Distal Radius Fractures. Orthopedic Clin North Am 1993;24:309-26.

6. Leibovic SJ, Geissler WB. Treatment of complex Intra-articular distal radius fractures. Orthopedic Clin North Am 1994;25:685-706.

7. Taleisnik J. The palmer cutaneous branch of the median nerve and the approach to the carpal tunnel. An anatomical study. J Bone Joint Surg [AM] 1973;55A:1212-7.

8. MacDonald R, Lichtman DM, Hanlon JJ, Wilson V. Complications of surgical release for carpal tunnel syndrome. J Hand Surg 1988;3:70-6

9. Carrol RE, Green DP. The significance of the palmar cutaneous nerve at the wrist. Clin Orthop 1972;83:24-8.

10. Das SK, Brown HG. In search of complications in carpal tunnel decompression. The Hand 1976;8:243-9.

11. Engber WB, Geiner JG. Palmar cutaneous branch of the ulnar nerve. J Hand Surg 1980;5:26-9.

12. Hobbs RA, Magnussen PA, Tonkin MA. Palmar Cutaneous Branch of the Median Nerve. J Hand Surg [Am] 1990;15A:38-43.

13. Last RJ. Anatomy Regional and Applied, 7th edn. New York: Churchill Livingstone, 1978.

14. McCabe SJ, Kleinert JM. The nerve of Henle. J Hand Surg 1990;15:784-8.

15. Kruschner S, Gelberman RH, Jennings C. Ulnar compression at the wrist. J Hand Surg 1988;13:577-9. 
16. Favero KJ, Gropper PT. Ulnar nerve laceration. A complication of carpal tunnel decompression. J Bone Joint Surg [Br] 1987;12B:239-41.

17. Lynch AC, Lipsomb PR. The carpal tunnel syndrome and colles fractures. JAMA 1963;185:363-6.

18. Vance RM, Gelberman RH. Acute ulnar neuropathy with fractures of the wrist. J Bone Joint Surg [Am] 1978;60:961-5.

19. Zoega H. Fractures of the lower end of the radius with ulnar nerve palsy. J Bone Joint Surg [Br] 1966;48:514-6.

20. Poisel S. Ursprung und Verlauf des R. muscularis des Nervus digitalis palmaris coumunis I (N. medianus). Chir Praxis 1974;18:471-4.

21. Lanz U. Anatomical variation of the median nerve in the carpal tunnel. J Hand Surg 1977;2:44-56.

22. Green DP, O'Brien ET. Open reduction of carpal dislocations: Indications and operative techniques. J Hand Surg 1978;3:250-65.

23. Rowland SA. Faciotomy: The treatment of compartment syndrome. In: Green DP, ed. Operative Hand Surgery. New York: Churchill Livingstone, 1993:661-94. 